\title{
AOR
}

Selected Papers of \#AolR2020:

The $21^{\text {st }}$ Annual Conference of the

Association of Internet Researchers

Virtual Event / 27-31 October 2020

\section{DOES ANYONE TALK ABOUT THE ISSUES ANYMORE? THE 2016 U.S. PRESIDENTIAL CANDIDATES' MESSAGING ON FACEBOOK AND TWITTER}

\author{
Jennifer Stromer-Galley \\ Syracuse University \\ Jeff Hemsley \\ Syracuse University \\ Patricia Rossini \\ University of Liverpool \\ Alex Smith \\ Syracuse University \\ Sarah Bolden \\ Syracuse University
}

\section{Motivation and Background}

Political campaigns use their Twitter and Facebook accounts to undertake a variety of different communication strategies, including mobilizing supporters to act, shaping journalists' and supporters' understanding of the candidate's policy positions, conveying the qualities and characteristics the candidate has to lead, and to differentiate themselves from their opponents (Stromer-Galley, 2019). In their advertisements, political campaigns historically have emphasized their policy positions more so than their own character and ability to lead (Johnston and Kaid, 2002). As campaigns have expanded their strategic communication to social media, we aim to better understand the dynamics of image and issue communication by the presidential candidates, and the public's engagement with policy topics.

Suggested Citation (APA): Stromer-Galley, J., Hemsley, J., Rossini, P., Smith, A., Bolden, S. (2020, October 28-31). Does Anyone Talk About the Issues Anymore? The 2016 U.S. Presidential Candidates' Messaging on Facebook and Twitter. Paper submitted to AolR 2020: The $21^{\text {th }}$ Annual Conference of the Association of Internet Researchers. Virtual Event: AolR. Retrieved from http://spir.aoir.org. 
The questions that drive our study are the following: (RQ1) Do candidates talk about policy (advocating for theirs or attacking their opponents') more so than their character and ability to lead (either their own ability or attacking that of their opponent)? Given the large number of candidates in the race, and the prior scholarship that suggests that the political parties own certain topics (Petrocik, 1996) and that political candidates will work to differentiate themselves from their opponents by owning certain policies (Arbour, 2013), we ask: (RQ2) When candidates talk on policy matters, what topics do they emphasize, and are there specific policy topics that certain candidates own? Because both Facebook and Twitter enable the public to engage the candidates' posts, we can further examine if the topics that candidates talk about are the ones engaged with by the public. Thus, we ask: (RQ3) Does the public engage more with certain policy topics over others? Finally, as candidates strategically use their social media accounts in different ways (Bossetta, 2018; Kreiss, Lawrence, McGregor, 2018), we ask: (RQ4) Do the candidates use their social media accounts in strategically different ways?

\section{Methods}

We studied the candidates who ran during the U.S. primaries in the 2016 presidential campaign. We collected the Facebook and Twitter posts by the 17 viable Republican and 5 viable Democratic candidates from September 1, 2015 through March 31st, 2016, when the field had narrowed dramatically to these finalists. We also collected all firstlevel public comments on candidates' Facebook walls and all retweets and @mentions of candidate posts on Twitter. We used human-supervised machine learning techniques to classify candidate posts on whether they were issue-focused, image-focused, along with several other categories. Our performance using this technique has an overall F1 score of .76 or higher on the image and the issue classifications for Twitter and for Facebook. We also built lexicons to classify candidate posts on nine different political topics (economy, foreign policy, social and cultural issues, social programs, safety, military, governance, immigration, and environment). We validated our lexicons by comparing human and machine scoring of topics on a random sample of posts and found agreement of $75 \%$ or better on each topic. Using clustering techniques as well as regression analysis, we examined the volume of posts that are image and issue focused, and what topics the different candidates analyze.

\section{Preliminary Results}

To answer RQ1 regarding whether candidates are more likely to post issue-focused messages as compared with image-focused messages, we analyzed a total of 59011 posts (14550 FB, $44461 \mathrm{TW}$ ) from 22 candidates. Of all of the posts, $27.42 \%$ were labeled as "issue." The rate was higher on Facebook at $34.39 \%$, whereas for Twitter it was $25.14 \%$.

To answer RQ2, we examined what topics candidates posted on and clustered them by percentage. We found noteworthy patterns in our preliminary analysis. For example, we noted that Bernie Sanders (Democrat) posted the most economy-focused messages, while Jeb Bush (Republican) was the most focused on foreign policy. We saw evidence for partisan ownership of some political issues. For example, Republicans were more 
likely to emphasize social and cultural issues as compared with Democrats. The Democratic candidates largely focused on domestic issues, with the exception of Jim Gilmore.

To answer RQ3, we will examine the topics the candidates posted on and the amount of engagement for those posts using engagement metrics of likes and retweets on Twitter and likes, shares, and comments on Facebook.

Preliminary results of RQ4 suggest that there are differences in what the candidates post on Facebook as compared with Twitter. For example, candidates in our set were more issue focused on Facebook than on Twitter. The platform difference is highly significant with a chi square test $(p=0.000)$. 


\section{Discussion and Conclusions}

Our results so far indicate that there is substantially less communication on social media about the issues than we have historically seen in candidates' paid advertising. The implication of this finding speaks to the shifting emphasis in U.S. politics to the character and personality of the candidates over their policy positions. Political communication scholars have long observed the shifting relationship between political candidates, their party, and the centrality of each to the voting public in the United States (Hacker, 2004; Jamieson, 1996). Moreover, the emphasis on communicating authenticity (Enli, 2015) and promoting celebrity (Abidin, 2018) on social media seems to extend to political candidates and the ways they communicate online. Functionally, our public sphere is deprived of articulation and deliberation of public concerns and how political elites propose to solve them.

We also see from our preliminary results that the candidates use their social media platforms for different strategic emphasis, with more policy discussion happening on Facebook. This may be because, as Kreiss, Lawrence, and McGregor (2018) find from their interviews with digital campaign staff, campaigns see Facebook as a platform where they are more likely to communicate with supporters and thus want to provide additional arguments to support their candidate based on policy. Twitter, on the other hand, is used to talk more directly with journalists and set the news agenda. Limitations to the study include the methodological challenges of lexicon-based classification, including the risk of low recall given the variance in words used to convey issues.

\section{References}

Abidin, C. (2018). Internet celebrity: Understanding fame online. United Kingdom: Emerald Publishing

Bossetta, M. (2018). The digital architectures of social media: Comparing political campaigning on Facebook, Twitter, Instagram, and Snapchat in the 2016 US election. Journalism \& Mass Communication Quarterly, 95(2), 471-496.

doi:10.1177/1077699018763307

Enli, G. (2015). Mediated authenticity: How the media constructs reality. Peter Lang.

Hacker, K. L. (2004). Introduction: The continued importance of the candidate image construct. In K. L. Hacker (Ed.), Presidential candidate images (pp. 1-20). Oxford, UK: Rowman \& Littlefield Publishers.

Jamieson, K H. (1996). Packaging the presidency (2nd Ed.). Oxford University Press.

Johnston, A., \& Kaid, L. L. (2002). Image ads and issue ads in U.S. presidential advertising: Using videostyle to explore stylistic differences in televised political ads from 1952 to 2000. Journal of Communication, 52, 281-300

Kreiss, D., Lawrence, R. G., \& McGregor, S. C. (2018). In their own words: Political practitioner accounts of candidates, audiences, affordances, genres, and timing of 
strategic social media use. Political Communication, 25 (1), 8-31.

doi:10.1080/10584609.2017.1334727.

Petrocik, J. R. (1996). Issue ownership in presidential elections, with a 1980 case study. American Journal of Political Science, 40 (3), 825-850.

Stromer-Galley, J. (2019). Presidential campaigning in the Internet age (2nd Ed.). Oxford University Press. 